\title{
Impacts of Bush Encroachment on Wildlife Species Diversity, Composition, and Habitat Preference in Ol Pejeta Conservancy, Laikipia, Kenya
}

\author{
Cyrus M. Kavwele, ${ }^{1}$ Johnstone K. Kimanzi, ${ }^{2}$ and Mwangi J. Kinyanjui ${ }^{1}$ \\ ${ }^{1}$ Department of Natural Resources, Karatina University, Karatina, Kenya \\ ${ }^{2}$ Department of Wildlife Management, University of Eldoret, Eldoret, Kenya \\ Correspondence should be addressed to Cyrus M. Kavwele; cyruskavwele@yahoo.com
}

Received 23 August 2017; Accepted 5 November 2017; Published 6 December 2017

Academic Editor: Daniel I. Rubenstein

Copyright (C) 2017 Cyrus M. Kavwele et al. This is an open access article distributed under the Creative Commons Attribution License, which permits unrestricted use, distribution, and reproduction in any medium, provided the original work is properly cited.

\begin{abstract}
Savannah ecosystems are currently facing a biome shift that changes grasslands to woody dominated landscapes, attributable to habitat degradation. In Ol Pejeta Conservancy (OPC), Euclea divinorum, an unpalatable and invasive woody species, is expanding to former savannah ecosystems with potential effects on herbivores key resources, wildlife species diversity, composition, and habitat use. We investigated wildlife species diversity, composition, and habitat preference or avoidance by wildlife in the conservancy. Infrared camera traps were deployed at the centroids of $2 \mathrm{~km}$ by $2 \mathrm{~km}, 50 \mathrm{~cm}$ above ground surface for 14 days and nights with 9 camera traps in each habitat type. Shannon wiener index revealed that wildlife species diversity was highest in E. divinorum dominated habitats and lowest in open grassland. Hierarchical Cluster Analysis revealed level of similarity in wildlife species composition between E. divinorum and mixed bushland. Jacobs index revealed that E. divinorum and mixed bushland were avoided by all guilds; however E. divinorum was significantly avoided while A. drepanolobium and open grassland were both preferred by all guilds. However, A. drepanolobium dominated habitats were significantly preferred compared to open grasslands. The findings are useful in management of sustainable ecosystems.
\end{abstract}

\section{Introduction}

Woody species encroachment has been described as gradual conversion of grasslands to woody and shrub dominated savannahs [1], a phenomenon that has been documented well in various parts of the world [2]. These increasingly changing grasslands [3] form persistent patches which alter composition and structure of flora in savannah ecosystems [4]. Overgrazing by exerting pressure on grazing lawns and increase in precipitation have shown positive correlation with woody species encroachment [5], hence touted as potential driver of the vegetation shifts. Further, soil conditions [6, 7] and fire suppression [8] among other perturbations are also attributable to this phenomenon.

According to Ward [9] an increase in woody species can significantly affect livestock and wildlife conservation efforts, as such, further indirectly or directly affecting livelihoods of the local people [10]. Particular facets of economy likely to be affected include but not limited to ecotourism, a key source of revenue in these ecosystems due to poor visibility, hence affecting game viewing experience [11]. From another ecological position, according to Wigley et al. [11], increase in woody species translates to increase in fuel wood, timber, and fencing material among other as well as increase in resource for browsing herbivores and structural diversity for avian biodiversity.

Even worse, encroachment in isolated ecosystems can result in decline and/or extinction of native species and can potentially affect species diversity, distribution, and abundance [12]. This also holds true according to Dalle et al. [13] where encroachment in savannah ecosystems poses a serious threat to ecosystems function especially tree-grass coexistence. Grass-tree balance influences grassland/rangeland 


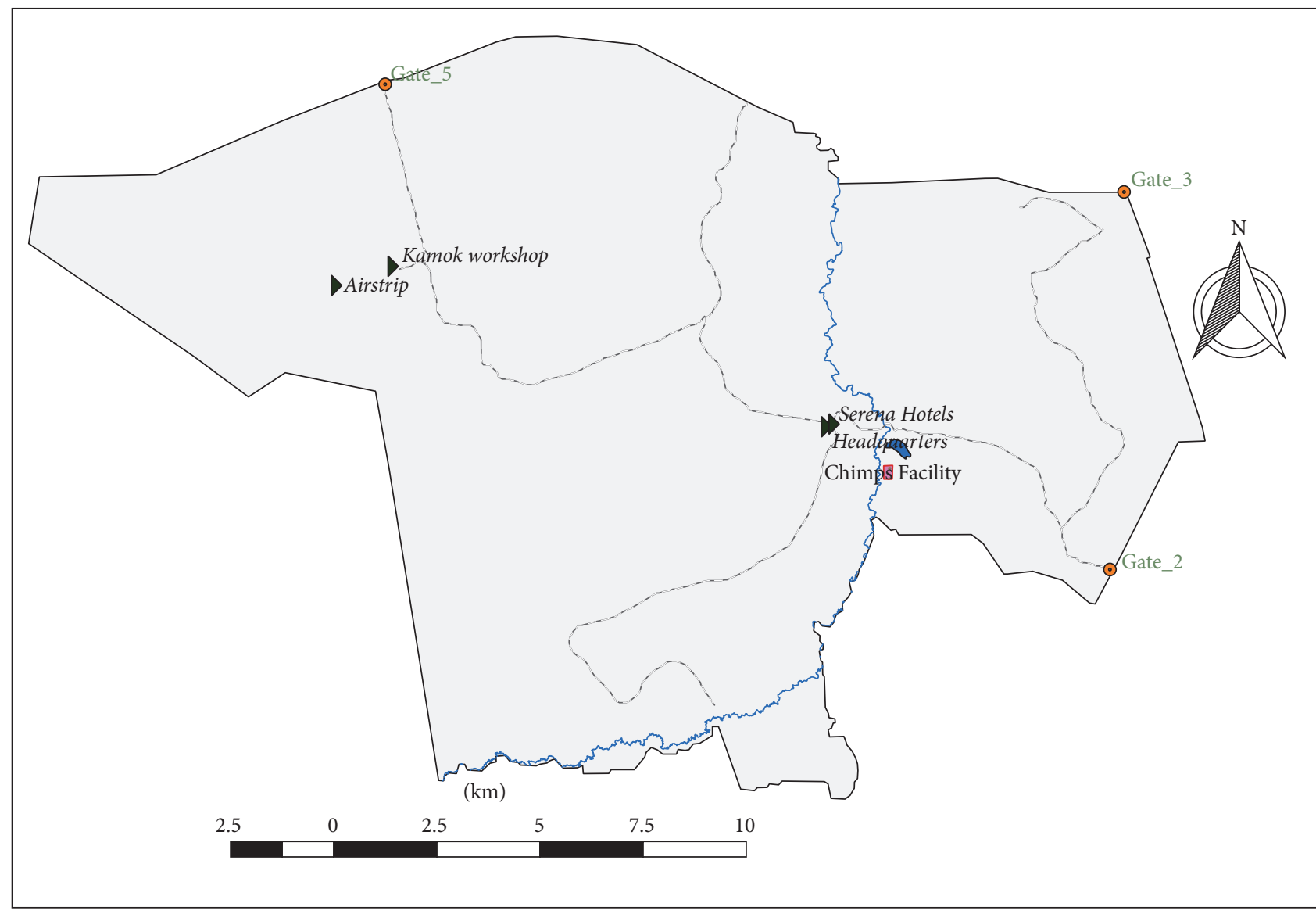

Chimps_House

Main_gates

Mash
Major_facilities

Major_roads

_ Ewaso_Nyiro_River
OPC_Boundary

FIGURE 1: Map of the study site. economic services, biodiversity conservation, and ecosystem function at local and landscape scales.

In Ol Pejeta Conservancy (OPC), encroachment by unpalatable $E$. divinorum encroachment towards Acacia drepanolobium, grasslands, and other open bushland vegetation cover types has become a concern for conservationists. Key resources for megafauna in these ecosystems especially the critically endangered Eastern black rhino, Diceros bicornis, International Union for Conservation of Nature (IUCN) red listing [14], and African elephants, Loxodonta africana, vulnerable (IUCN) red listing [15], among other herbivores can potentially be affected. This encroachment can further reduce the available ranging lands and to some extent exterminate some of the wild flora and fauna. Here, we investigated (a) wildlife species diversity and evenness in encroached and nonencroached habitats, (b) wildlife species composition in encroached and nonencroached habitats, and (c) habitat preference or avoidance by various feeding guilds within the conservancy. The findings demonstrate impacts of bush encroachment on biodiversity, hence, beneficial to conservationists.

\section{Methods}

2.1. Study Site. This study was undertaken in Ol Pejeta Conservancy in Laikipia County, Central Kenya, as shown in Figure 1 . The property which covers 90,000 acres $\left(360 \mathrm{~km}^{2}\right)$ lies in between Mt. Kenya and Aberdares (at $0^{\circ} 7.288^{\prime} \mathrm{N}$, $36^{\circ} 42.384^{\prime} \mathrm{E}$ and $\left.0^{\circ} 8.634^{\prime} \mathrm{N}, 37^{\circ} 0.605^{\prime} \mathrm{E}\right)\left(0^{\circ} 1.831^{\prime} \mathrm{S}, 36^{\circ}\right.$ $46.578^{\prime} \mathrm{E}$ and $\left.0^{\circ} 5.7025^{\prime} \mathrm{S}, 37^{\circ} 2.492^{\prime} \mathrm{E}\right)$. It has an average altitude of $1810 \mathrm{~m}$, mean annual rainfall of $739 \mathrm{~mm}$, and mean maximum and minimum temperatures of $28^{\circ} \mathrm{C}$ and $12^{\circ} \mathrm{C}$, respectively. It is a private owned conservancy, chiefly, a sanctuary for black rhinos (Diceros bicornis). However, other wild animals are also conserved in the same property composed of various feeding guilds such as mixed feeders, carnivores, grazers, and browsers. It is also a sanctuary for chimpanzee (Pan troglodytes) providing refuge site for seized chimps from black markets. It has one permanent river flowing through the conservancy as well as various manmade water holes to supplement water scarcity in dry spells.

Habitat cover types include grasslands, Acacia drepanolobium, A. xanthophloea, Euclea divinorum, and mixed bushlands. The conservancy is surrounded by an electric fence 


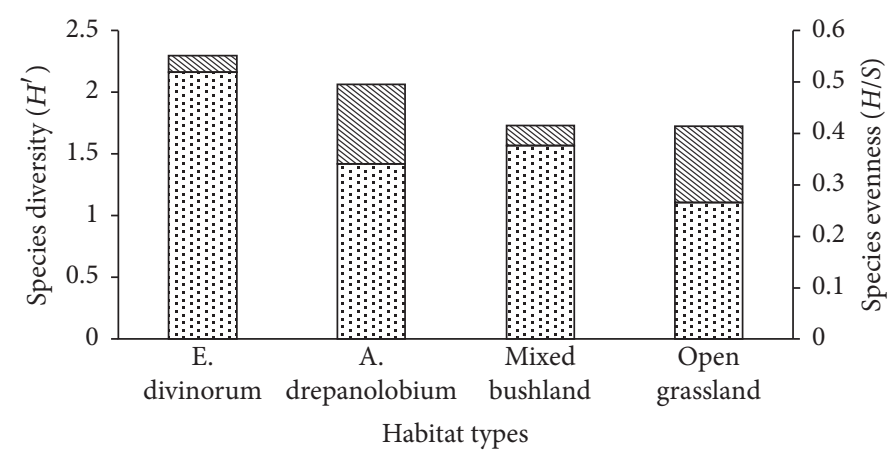

FIGURE 2: Wildlife species diversity (left $y$ axis) and wildlife species evenness (right $y$ axis) in different habitats in OPC.

with three "corridors" to allow movement of wild animals in and out of OPC (but movement of rhino species is restricted due to the risks involved). The conservancy is surrounded by agropastoral communities and towards the north by other adjoining conservancies.

2.2. Data Collection and Analysis. The entire conservancy was overlaid on $2 \times 2 \mathrm{~km}$ grid as shown in Figure 1 (map) and centroids of each grid were identified. At every centroid, motion triggered infrared camera traps of Reconyx Rapidfire $\mathrm{RM}^{45}$ model were deployed systematically taking into cognisance of animal trails to capture wildlife species within given cover types. Camera traps were set to take photos with no delay and remain active for $24 \mathrm{hrs}$ at $50 \mathrm{~cm}$ above the ground surface either attached to a tree using elastic strings (cords) or housed in a metal cage in case of grassland areas. They remained in the field for 14 consecutive days and nights though they were checked on the 7 th day for battery charge level, remaining storage size in secure cards (SD), and any other malfunctions occasioned by knocking of the traps by rhinos or elephants. A total of 9 camera traps were deployed in each habitat type, namely, open grassland, E. divinorum, A. drepanolobium, and mixed bushland. Upon realising low battery charge or near filled up storage there were replacements of such to avoid loss of data due to nonperforming camera traps. Immediately after removal of camera traps from the field, all photographic data were downloaded and further sorted into species name, size, time, and habitat type the camera trap was deployed in. Further, duplicates were removed where thirty (30) minutes after the last photo was taken was considered as another photographic event.

After data cleaning, species diversity and composition using Shannon Weiner index (where if index is 5 it implies highest diversity and if it is 1 it implies lowest diversity) [16] and Hierarchical Cluster Analysis [17], respectively, were performed in Paleontological Statistics Software Package for Education and Data Analysis (PAST) software while habitat preference or avoidance was performed using Jacobs' index [18]. Further, Jacobs' index values were tested for significance preference or avoidance (where +1 implies maximum preference while -1 implies maximum avoidance) using $t$ tests against means of zero (0) in $\mathrm{R}$ version 3.1.2. Prior to these tests, normal distribution and homogeneity of variance were performed to ensure that conditions for parametric tests were not violated [19]. Overlay of grids on the spatial extent of the conservancy was performed in Quantum Geographic Information Systems (QGIS) platform version 2.8.2.

\section{Results}

3.1. Wildlife Species Diversity and Evenness. Shannon Weiner index revealed highest wildlife species diversity in $E$. divinorum dominated habitats $\left(H^{\prime}=2.291\right)$, followed by $A$. drepanolobium habitats $\left(H^{\prime}=2.058\right)$, mixed bushland $\left(H^{\prime}=\right.$ $1.728)$, and least wildlife species diversity in open grassland $\left(H^{\prime}=1.715\right)$. Wildlife species evenness $(H / S)$ was highest in area under E. divinorum $(H / S=0.5201)$, followed by mixed bushland $(H / S=0.3751)$ and then closely followed by $A$. drepanolobium $(H / S=0.3404)$ and finally open grassland $(H / S=0.2647)$ as shown in Figure 2.

3.2. Wildlife Species Composition. Hierarchical Cluster Analysis (HCA) compared wildlife species composition (common wildlife species) across the four habitat types, namely, E. divinorum, A. drepanolobium, mixed bushland, and open grassland. Results revealed that E. divinorum and mixed bushland habitats shared $45 \%$ similarity in wildlife species composition. Additionally, E. divinorum habitat and mixed bushland shared 39\% similarity in wildlife species composition with $A$. drepanolobium dominated habitat. On the other hand, open grassland habitat shared $27 \%$ similarity in wildlife species composition with three habitat types, namely, E. divinorum, A. drepanolobium, and mixed bushland as shown in Figure 3.

\subsection{Habitat Preference or Avoidance by Various Feeding Guilds} in OPC. Jacobs index revealed that carnivores preferred A. drepanolobium $(D=0.469)$ mostly followed by open grassland $(D=0.327)$ and least preferred mixed bushland $(D=0.066)$ but avoided $E$. divinorum dominated areas $(D=$ -0.698) (Figure 4(a)). Grazers showed great preference for open grassland $(D=0.773)$ and $A$. drepanolobium $(D=$ $0.040)$ but avoided $E$. divinorum $(D=-0.917)$ and mixed bushland $(D=-0.192)$ habitats (Figure $4(b))$. 


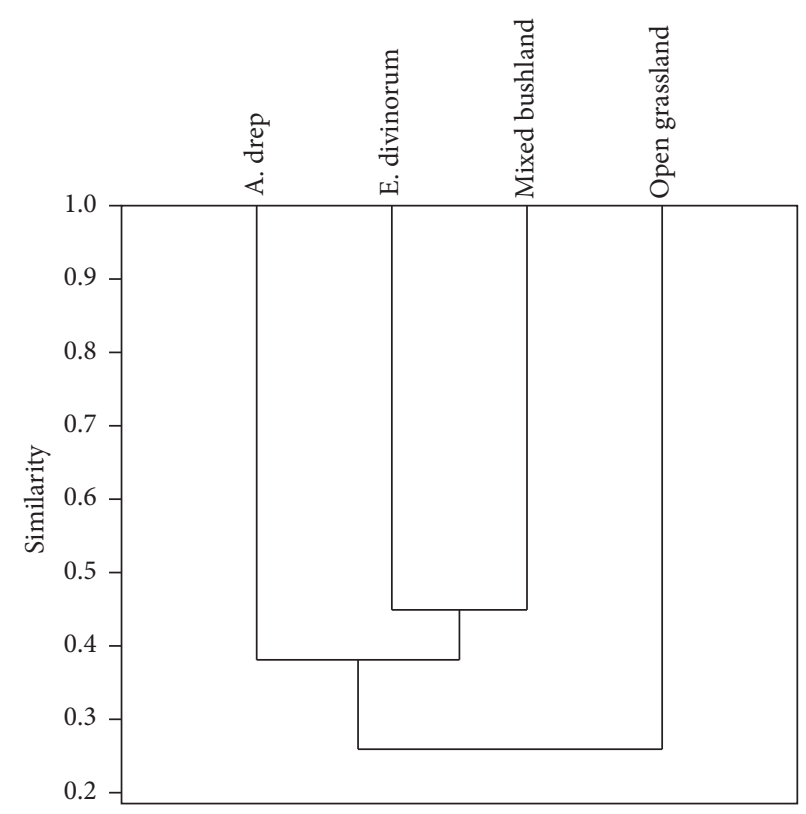

FIGURE 3: Percentage similarity in wildlife species composition of 4 habitats in OPC.

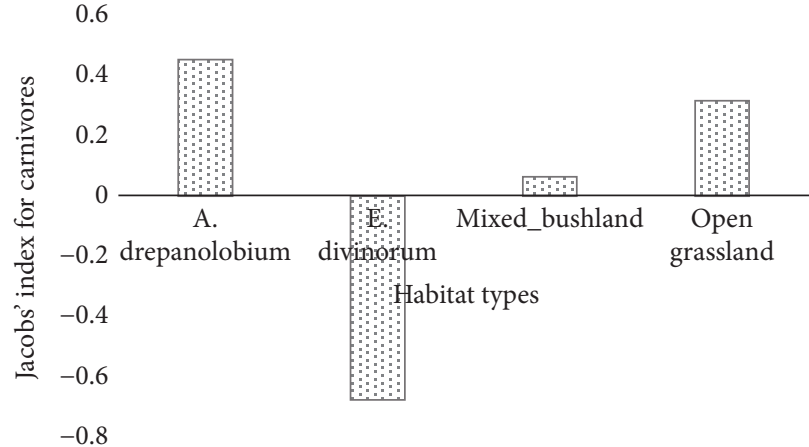

(a)

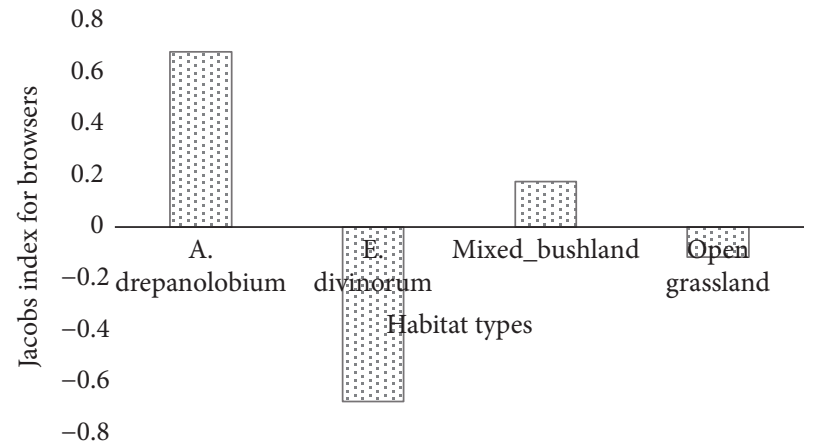

(c)

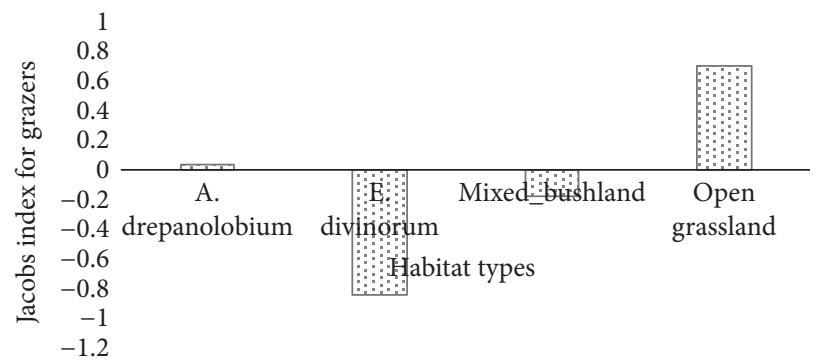

(b)

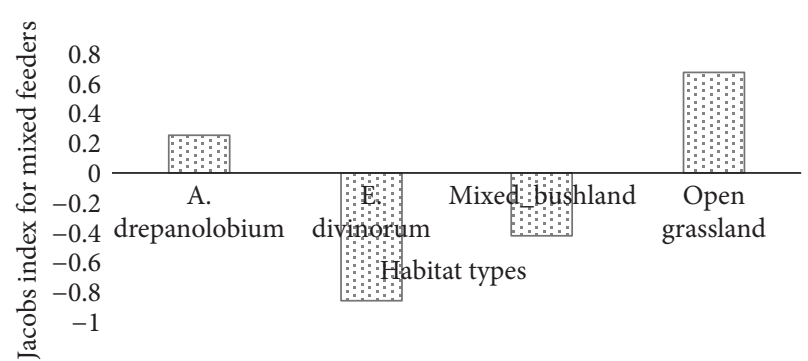

(d)

FIGURE 4: Habitat preference or avoidance (Jacobs' index) for (a) carnivores, (b) grazers, (c) browsers, and (d) mixed feeders in OPC.

Browsers showed preference for A. drepanolobium $(D=$ $0.674)$ and mixed bushland habitat $(D=0.175)$ but avoided both $E$. divinorum $(D=-0.673)$ and open grasslands $(D=$ -0.116 ) dominated habitats (Figure 4(c)). However, mixed feeders preferred habitats dominated by open grassland $(D=$ 0.688 ) and $A$. drepanolobium $(D=0.523)$ but avoided $E$. divinorum $(D=-0.858)$ and mixed bushland $(D=-0.420)$ dominated habitats (Figure 4(d)). A total of thirty (30) wildlife species were recorded as per the table in the supplementary material showing detection and nondetection of wildlife species in various habitat cover types.

Mean preference or avoidance revealed that E. divinorum and mixed bushland were avoided; however, E. divinorum was significantly avoided $\left(t_{1}=2.253\right.$, d.f. $=3$, and 


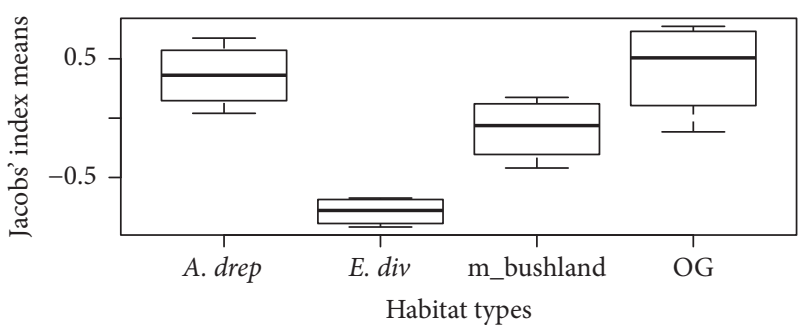

Figure 5: Jacobs index means for all guilds across the habitat types.

$p<0.01)$ compared with mixed bushland $\left(t_{1}=2.353\right.$, d.f. $=3$, and $p=0.27)$. On the other hand, A. drepanolobium and open grassland were both preferred by all feeding guilds; however, A. drepanolobium dominated habitats were significantly preferred $\left(t_{1}=2.353\right.$, d.f. $=3$, and $\left.p=0.03\right)$ compared to open grasslands $\left(t_{1}=2.353\right.$, d.f. $=3$, and $p=$ $0.06)$ as shown in Figure 5.

\section{Discussions}

Wildlife species diversity and evenness were highest in $E$. divinorum dominated areas compared to other habitat types. This is attributable to existence of resource rich patches that are hardly accessed by most wildlife species. As such, attraction of several wildlife species into this dense vegetation (E. divinorum) contributed to higher diversity chiefly small carnivores. Animals use cues such as landscape structure and vegetation structure like tree species phenology, resource availability (probability of encounter, quantity, and quality), and predator/parasite risks among others in order to explore a given habitat type. This implies that spatial and temporal habitat heterogeneity drives faunal species diversity and composition from local to regional to global scales. Hence, aggregation of resources may create dynamic impacts where these small sites/patches become a focus for higher proportion of faunal diversity and composition [20]. According to Sirami et al. [21] savannah ecosystems are diverse in structure and floral composition; hence different guilds will use different habitats based on their requirements.

Animals have different preference to certain habitats [22] as a function of direct and indirect effects of prey availability, detectability/cover, and resource availability [23]. Spatial heterogeneity of ecosystem is important for maintenance of diverse wild animal species and acts as buffer against changes in resources availability for wild animals in era of climate change [24]. On the other hand, woody encroachment can potentially change this heterogeneity and affect wide range of wild animals.

Similarity in wildlife species composition was highest between E. divinorum and mixed bushland habitats. These two habitat types have nearly homogeneous vegetation structure (dense canopy). This phenomenon is an illumination to higher percentage similarity in wildlife species composition in both E. divinorum and mixed bushland dominated areas due to nearly similar structure of the vegetation (canopy and dense bushland) providing ideal habitats for wildlife species which require such areas. According to Dupuch et al. [25], prey and predator can explore freely across habitats that differ in resource quantity, quality, and inherent habitat risks. As such, predators' movement and habitat selection are as a function of prey density, competition level, cover, and inherent risks while prey habitat selection and movement are balance of forage quality (benefits of foraging) and risk of predation [26].

On the other hand, habitats dominated by A. drepanolobium and open grassland were preferred by feeding guilds majorly herbivores due to their associated lesser predation risk. This is chiefly influenced by presence of relatively open landscapes allowing prey to detect predators from a distance and hence maintain safer flight distance (improved visibility). The phenomenon is consistent with other findings according to Dupuch et al. [25], where prey habitat selection is largely influenced by the need to minimise predation risks over forage quality. As such, these factors influence preference of habitats that offer significant benefits for most wildlife species.

\section{Conclusion and Recommendations}

The study revealed that bush encroachment by E. divinorum had impact on species diversity, composition, and habitat selection. In particular, species diversity was highest in $E$. divinorum dominated areas and least in open grasslands, a positive impact, albeit long term impacts are unknown. Likewise, percentage similarity in species composition was highest between E. divinorum and mixed bushland dominated habitats. Further, feeding guilds avoided areas dominated by E. divinorum but preferred A. drepanolobium and open grassland dominated habitats; hence, bush encroachment by $E$. divinorum affected habitat suitability; thus it has a negative impact. Based on this finding, active management of the encroaching species is recommended. Further studies on activity budget of wildlife species to ascertain how habitat types are being used are key. Additionally, long term study to provide insights into the effect of seasonality on species diversity dynamics across various land cover types in the conservancy is crucial. This information will be vital in designing habitat management protocols for sustainable ecosystem management.

\section{Conflicts of Interest}

The authors declare no conflicts of interest.

\section{Acknowledgments}

This study was funded by Rufford Foundation, United Kingdom (UK), Grant no. 19422-1. The authors are grateful to Carol Ngw'eno and Bernard Chira from Ol Pejeta Conservancy (OPC) for allowing them to carry out research in their property and Andrew Bradley and Dan Smith both from Bangor University for their help in camera trap image classification. 


\section{Supplementary Materials}

Table 1. Wildlife species detection or nondetection across the various habitat cover types. (Supplementary Materials)

\section{References}

[1] A. T. Hudak, C. A. Wessman, and T. R. Seastedt, "Woody overstorey effects on soil carbon and nitrogen pools in South African savanna," Austral Ecology, vol. 28, no. 2, pp. 173-181, 2003.

[2] S. Archer, T. W. Boutton, and K. A. Hibbard, "Trees in grasslands: biogeochemical consequences of woody plant expansion," in Global Biogeochemical Cycles in the Climate System, pp. 115-137, Academic Press, San Diego, 2001.

[3] I. A. Dickie, S. A. Schnitzer, P. B. Reich, and S. E. Hobbie, "Is oak establishment in old-fields and savanna openings context dependent?” Journal of Ecology, vol. 95, no. 2, pp. 309-320, 2007.

[4] S. R. Wangen and C. R. Webster, "Potential for multiple lag phases during biotic invasions: Reconstructing an invasion of the exotic tree Acer platanoides," Journal of Applied Ecology, vol. 43, no. 2, pp. 258-268, 2006.

[5] D. F. Joubert, A. Rothauge, and G. N. Smit, "A conceptual model of vegetation dynamics in the semiarid Highland savanna of Namibia, with particular reference to bush thickening by Acacia mellifera," Journal of Arid Environments, vol. 72, no. 12, pp. 22012210, 2008.

[6] M. Sankaran, J. Ratnam, and N. Hanan, "Woody cover in African savannas: The role of resources, fire and herbivory," Global Ecology and Biogeography, vol. 17, no. 2, pp. 236-245, 2008.

[7] G. Oba, E. Post, P. O. Syvertsen, and N. C. Stenseth, "Bush cover and range condition assessments in relation to landscape and grazing in southern Ethiopia," Landscape Ecology, vol. 15, no. 6, pp. 535-546, 2000.

[8] O. W. Van Auken, "Shrub invasions of North American semiarid grasslands," Annual Review of Ecology, Evolution, and Systematics, vol. 31, pp. 197-215, 2000.

[9] D. Ward, "Do we understand the causes of bush encroachment in African savannas?" African Journal of Range \& Forage Science, vol. 22, no. 2, pp. 101-105, 2005.

[10] A. T. Hudak and C. A. Wessman, "Textural analysis of high resolution imagery to quantify bush enroachment in Madikwe Game Reserve, South Africa, 1955-1996," International Journal of Remote Sensing, vol. 22, no. 14, pp. 2731-2740, 2001.

[11] B. J. Wigley, W. J. Bond, and M. T. Hoffman, "Bush encroachment under three contrasting land-use practices in a mesic South African savanna," African Journal of Ecology, vol. 47, no. 1, pp. 62-70, 2009.

[12] D. R. Towns, I. A. E. Atkinson, and C. H. Daugherty, "Have the harmful effects of introduced rats on islands been exaggerated?" Biological Invasions, vol. 8, no. 4, pp. 863-891, 2006.

[13] G. Dalle, B. L. Maass, and J. Isselstein, "Encroachment of woody plants and its impact on pastoral livestock production in the Borana lowlands, southern Oromia, Ethiopia," African Journal of Ecology, vol. 44, no. 2, pp. 237-246, 2006.

[14] R. Emslie, "Diceros bicornis, The IUCN Red List of Threatened Species 2012," 2012. e.T6557A16980917. Downloaded on 17April, http://dx.doi.org/10.2305/IUCN.UK.2012.RLTS .T6557A16980917.en. 2016.
[15] J. Blanc, "Loxodonta africana, The IUCN Red List of Threatened Species 2008,"2008. e.T12392A3339343. http://dx.doi.org/ 10.2305/IUCN.UK.2008.RLTS.T12392A3339343.en.Downloaded on 17 April 2016.

[16] C. E. Shannon and W. Weaver, The Mathematical Theory of Communication, University of Illinois Press, Chicago, 1949.

[17] H. G. Gauch, Multivariate Analysis in Community Ecology, Cambridge University Press, Cambridge, UK, 1982.

[18] J. Jacobs, "Quantitative measurement of food selection - A modification of the forage ratio and Ivlev's electivity index," Oecologia, vol. 14, no. 4, pp. 413-417, 1974.

[19] F. Palomares, M. Delibes, E. Revilla, J. Calzada, and J. M. Fedriani, "Spatial ecology of iberian lynx and abundance of european rabbits in southwestern spain," Wildlife Monographs, vol. 148, pp. 1-36, 2001.

[20] D. J. D. Natusch, J. A. Lyons, G. Brown, and R. Shine, "Communally nesting migratory birds create ecological hot-spots in Tropical Australia," PLoS ONE, vol. 11, no. 10, Article ID e0162651, 2016.

[21] C. Sirami, C. Seymour, G. Midgley, and P. Barnard, "The impact of shrub encroachment on savanna bird diversity from local to regional scale," Diversity and Distributions, vol. 15, no. 6, pp. 948-957, 2009.

[22] A. R. E. Sinclair, S. Mduma, and J. S. Brashares, "Patterns of predation in a diverse predator-prey system," Nature, vol. 425, no. 6955, pp. 288-290, 2003.

[23] W. J. Ripple and R. L. Beschta, "Wolves and the ecology of fear: Can predation risk structure ecosystems?" Bioscience, vol. 54, no. 8, pp. 755-766, 2004.

[24] G. Wang, N. T. Hobbs, R. B. Boone et al., "Spatial and temporal variability modify density dependence in populations of large herbivores," Ecology, vol. 87, no. 1, pp. 95-102, 2006.

[25] A. Dupuch, L. M. Dill, and P. Magnan, "Testing the effects of resource distribution and inherent habitat riskiness on simultaneous habitat selection by predators and prey," Animal Behaviour, vol. 78, no. 3, pp. 705-713, 2009.

[26] P. A. Abrams, "Habitat choice in predator-prey systems: Spatial instability due to interacting adaptive movements," The American Naturalist, vol. 169, no. 5, pp. 581-594, 2007. 

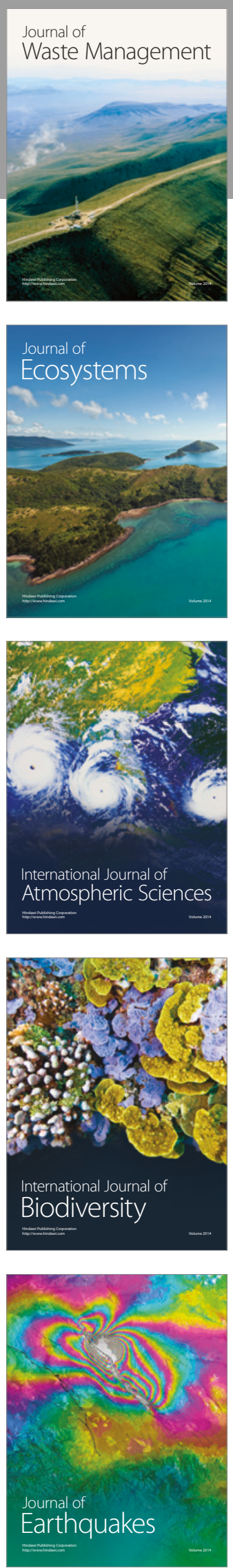
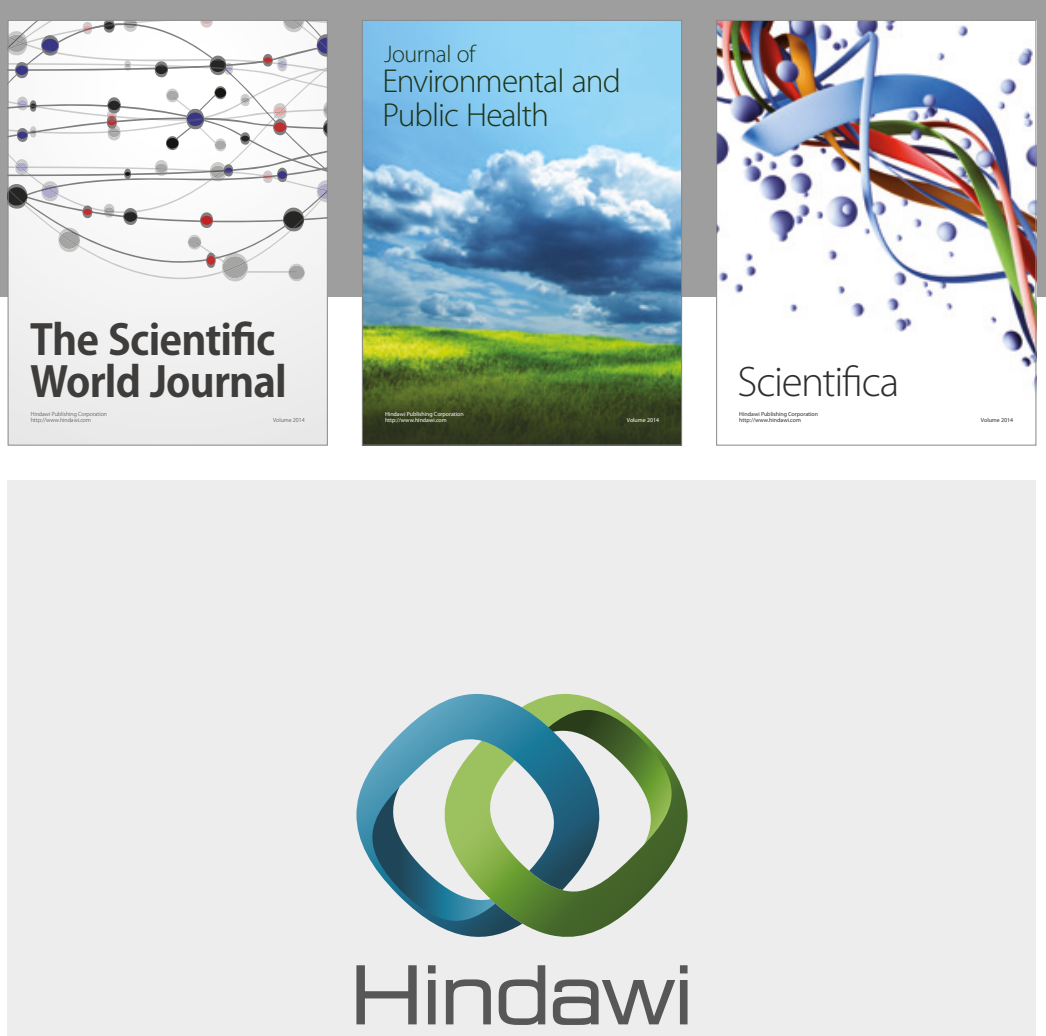

Submit your manuscripts at

https://www.hindawi.com
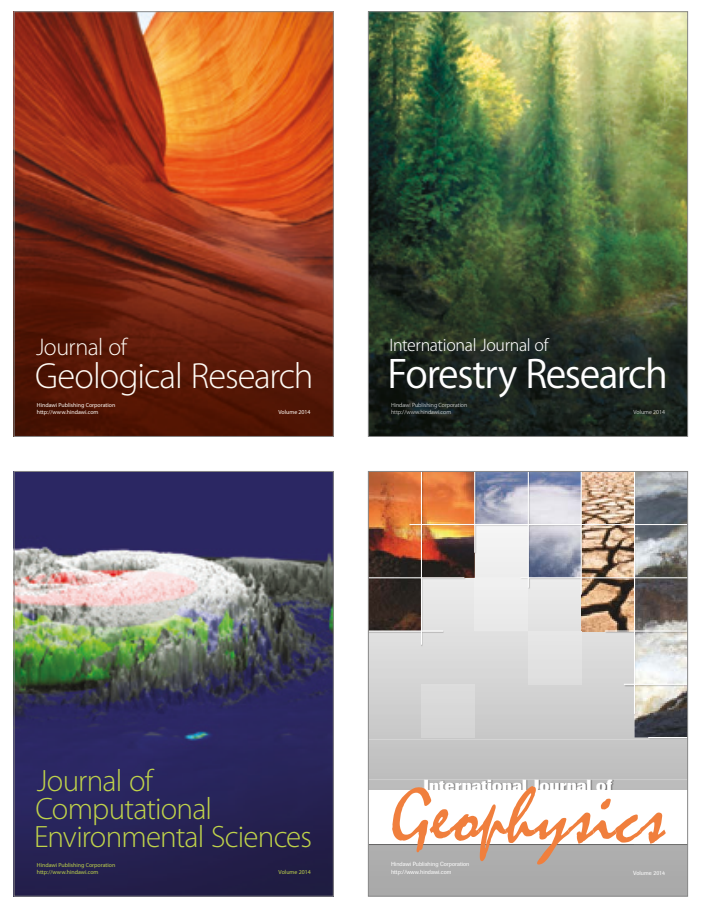
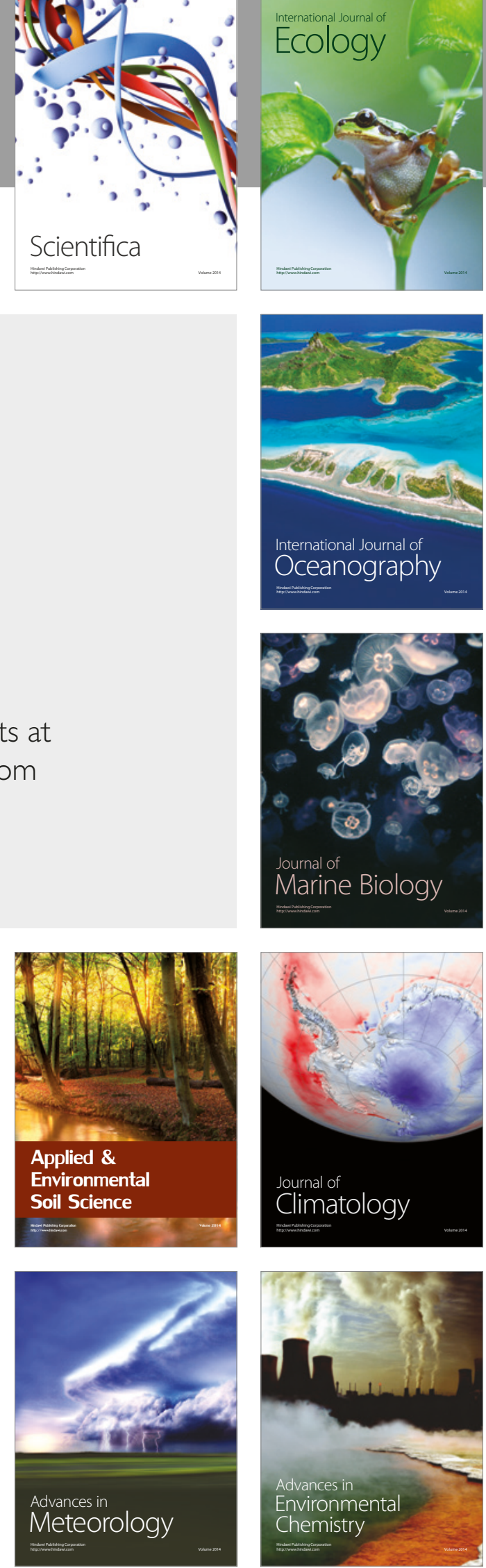